\title{
Viable Second Trimester Cervical Ectopic Pregnancy Managed Successfully with Uterine Preservation: Case Report
}

\author{
Suzan Elsharkawy ${ }^{*}$, Abdullah Elrashidy², Nazem Badran33, Gawed Ekbal'3, Shahda Yakob3, \\ Salamah Elnagar ${ }^{4}$, Ashraf Elaggan ${ }^{5}$, Amr Mostafa5, Mohamed Abdelaziz ${ }^{6}$ \\ ${ }^{1}$ Assistant Professor of Obstetrics and Gynecology Alexandria University, ARE and Consultant of Obstetrics and Gynecology, \\ Hail General Hospital, Hail, KSA \\ ${ }^{2}$ Consultant of Urology, King Khalid Hospital, Hail, KSA \\ ${ }^{3}$ Consultants of Obstetrics and Gynecology, Alkasim Maternity Hospital, Alkasim, KSA \\ ${ }^{4}$ Consultants of Obstetrics and Gynecology, Hail General Hospital, Hail, KSA \\ ${ }^{5}$ Consultants of Radiology, King Salman Hospital, Hail, KSA \\ ${ }^{6}$ Faculty of Medicine Mansoura University, Mansoura, Egypt \\ Email: ${ }^{\star}$ _abdelrahim00@alexmed.edu.eg
}

How to cite this paper: Elsharkawy, S., Elrashidy, A., Badran, N., Ekbal, G., Yakob, S., Elnagar, S., Elaggan, A., Mostafa, A. and Abdelaziz, M. (2021) Viable Second Trimester Cervical Ectopic Pregnancy Managed Successfully with Uterine Preservation: Case Report. Open Journal of Obstetrics and Gynecology, 11, 1236-1247. https://doi.org/10.4236/ojog.2021.119117

Received: August 27, 2021

Accepted: September 24, 2021

Published: September 27, 2021

Copyright $\odot 2021$ by author(s) and Scientific Research Publishing Inc. This work is licensed under the Creative Commons Attribution International License (CC BY 4.0).

http://creativecommons.org/licenses/by/4.0/ (c) (i) Open Access

\begin{abstract}
Cervical pregnancy is a rare clinical entity that accounts for less than $1 \%$ of all ectopic pregnancies. It results from implantation of the blastocyst in the cervical canal below the level of the internal os. Although non-tubal ectopic pregnancies account for only $5 \%$ of ectopics, they contribute to a significant morbidity. The cornerstone in the management of cervical ectopic is early diagnosis by high index of suspension and a qualified sonographer. Management options for cervical ectopic pregnancies range from conservative drug treatment to radical hysterectomy. Over the last few years, the mortality and morbidity rates of ectopic pregnancies have been reduced. This is mainly due to the early recognition of the condition and the wide availability of minimally invasive surgical procedures. We present a case of a 33-year-old woman that was 16 weeks pregnant. She presented initially with recurrent vaginal bleeding followed by minimal lower abdominal pain. Her early US scans were misleading. Several weeks later, a follow up MRI scan suggested cervical ectopic. She was managed surgically with uterine preservation.
\end{abstract}

\section{Keywords}

Ectopic Pregnancy, Cervical Ectopic, Uterine Artery Embolization, Hystroscopic Resection, Conservative Management of Ectopic, Methotrexate, Cervical Tamponade, Bakri Balloon, Cervical Cerclage 


\section{Introduction}

As rare as occurring once in 1000 to 95,000 pregnancies [1], cervical ectopic pregnancy (CEP) is an uncommon clinical situation in gynecology. CEP is the second rarest subtype of ectopic pregnancy following abdominal ectopic [2]. The exact causes are not clear but many theories have been proposed, some supposing an unreceptive endometrium, rapid transport of the fertilized oocyte to the cervical canal before nidation, others questioning the damage to the cervix and the endometrium caused by operative procedures like dilatation \& curettage or operative delivery. The risk factors to develop CEP are multiple and include: previous ectopic pregnancy, Asherman's syndrome, intrauterine device use, history of pelvic inflammatory disease, smoking, anatomic anomalies and in vitro fertilization [3] [4]. Although cervical pregnancies are rare, increased number of cases being reported because of risk factors like high cesarean section rate and increased use of assisted reproductive techniques for management of infertility. According to one review, the incidence of cervical pregnancy is $0.1 \%$ among in vitro fertilization pregnancies [5]. Due to its rarity, the absolute risk remains low and the association with the above factors remains small, but CEP is a life threatening condition that must be excluded in any woman presenting with vaginal bleeding, lower abdominal pain and missed period. Early diagnosis has been the cornerstone for conservative management and reduction of morbidity and mortality, while delay in the diagnosis can cause a bloody compromise that may require hysterectomy by up to $50 \%$ of cases [6] [7]. We present a CEP case that had a delay in the diagnosis till it reached seventeen weeks gestation.

\section{Case Report}

33-year-old female patient, G4 p3 was presented in emergency ward with a painless attack of extensive vaginal bleeding, her obstetric history has three deliveries; the first one was preterm vaginal, the second was by caesarian section (CS) and the last one was vaginal birth after CS (VBAC); which preceded this current pregnancy by only 2 months. She also had done a myomectomy surgery for a $7 \mathrm{~cm}$ submucous myoma after her first child.

The condition started when she had an attack of moderate vaginal bleeding after five weeks of amenorrhea (7/4/2021), she sought medical advice when she performed a trans-abdominal ultrasound (TA-US) that showed an empty uterus and a human chorionic gonadotropin (HCG) level was $672 \mathrm{mIU} / \mathrm{ml}$, so she was given progesterone IM injection to control the bleeding and asked to follow up after one week to repeat ultrasonic examination.

On the next week (13/4/2021), the BHCG was $8498 \mathrm{mIU} / \mathrm{ml}$, and a small sac with no fetal pole was noticed using the TA-US, nothing abnormal was suspected at that time and again the patient was sent back home. On her next appointment (5/5/2021), a cervical gestational sac was obvious on trans-abdominal us, which contained a pulsating fetal pole of 8 weeks gestation; yet her doctor was not able to be sure of the diagnosis of cervical ectopic and the patient was 
referred for senior consultation (Figure 1).

Unfortunately, the consultant assured her about this pregnancy (from 26/5 to $14 / 6 / 2021$ ), alleging it was normal with normal placentation, and said "it is a boy!!”, which was a desired sex for the patient, so she missed a precious chance for early intervention and kept following this false assurance till she reached 15 weeks (Figure 2). Then she had a severe attack of vaginal bleeding and admitted to a primary care hospital emergency ward on the $14^{\text {th }}$ of June 2021 .

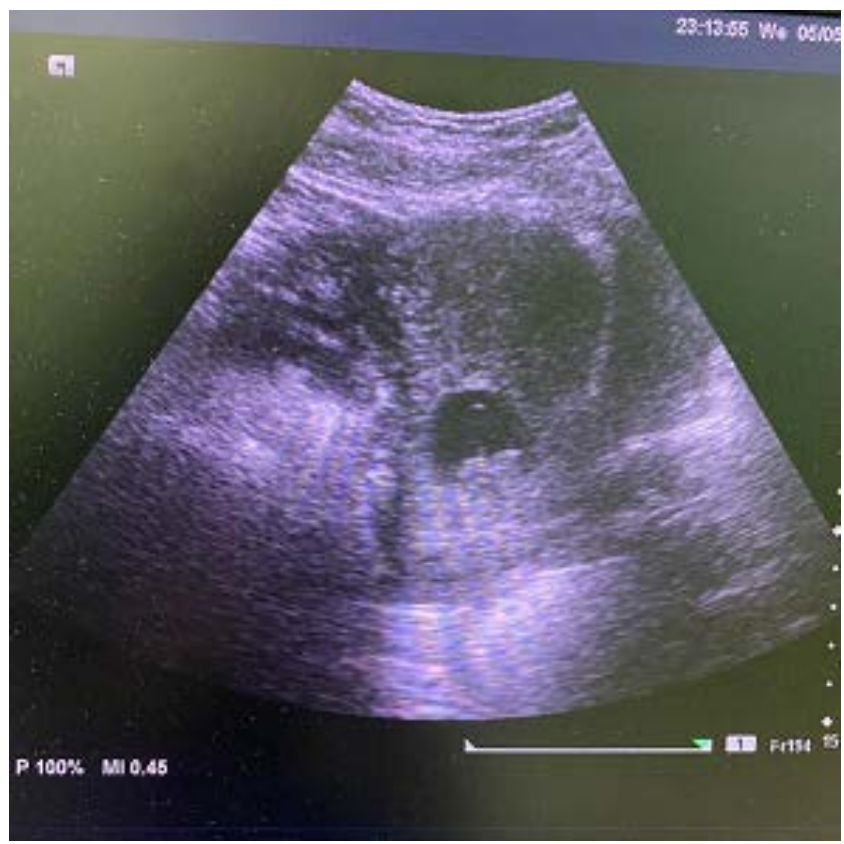

Figure 1. Early trans-abdominal US showed obvious cervical ectopic pregnancy with intact 8 weeks fetus. Despite this, the diagnosis was delayed 8 weeks later.

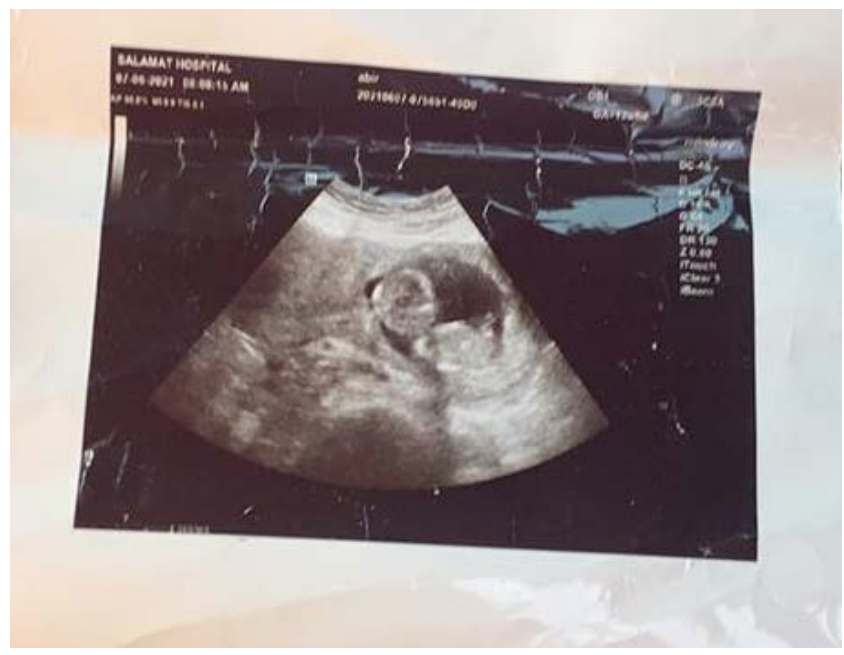

Figure 2. A follow up trans-abdominal US of the same case showing the fetus (about 14 week) resting in the ballooned cervix on the right side of the image. On the left side, the uterus is empty with closed internal os. 
On admission, her blood pressure was 119/78 $\mathrm{mmHg}$, pulse $81 \mathrm{~b} / \mathrm{min}$, oxygen saturation $98 \%$, respiratory rate $20 \mathrm{breath} / \mathrm{min}$ and temperature $37 \mathrm{C}$. On examination, moderate vaginal bleeding was found, without any pain per-vaginal examination (PV) revealed ballooned cervical canal with opened external cervical os by $2 \mathrm{~cm}$. transvaginal us showed ballooned cervical canal occupied with a second trimester pregnancy, the placenta was lying on the anterior cervical wall extended to cover the external cervical os with enhanced vascularity and localized hematoma underneath as shown with color Doppler waves. Trans-abdominal us showed a 15-week normal looking male fetus surrounded with average amount of liquor, sitting peacefully in a hugely distended cervical canal!! The uterus was overriding the pregnancy, empty cavity and closed internal os with a small interstitial fibroid $3 \mathrm{~cm}$.

She was given Cyclokapron 2 ampules intravenous (500 mg/ampule) and luton depot 1 ampule intra-muscular ( $250 \mathrm{mg} / \mathrm{ampule}$ ) immediately to control the bleeding, then her investigations were: $\mathrm{O}+$ ve blood group, $\mathrm{Hb} 12.4 \mathrm{~g} / \mathrm{dl}$, platelets 208,000/uL, INR 1.02, ALT $33 \mathrm{U} / \mathrm{L}$, AST $16 \mathrm{U} / \mathrm{L}$, serum creatinine 58.5 umol/L. she was generally stable and after 30 minutes the vaginal bleeding stopped, giving a chance for further evaluation through emergency MRI on the next day to be sure of the diagnosis. Although the US picture was crystal clear, but due to the exceptional gestational age of the fetus, more advanced imaging diagnosis was essential to differentiate between cervical ectopic or low lying placenta.

On 16/6/2021, MRI was done without dye and reported a cervical ectopic pregnancy 15 weeks gestation totally present in cervical canal, Figure 3. The placenta was located at the anterior and right lateral aspect of the cervical wall, with marked stretching, thinning of the underlying myometrium and focal interruptions of the myometrial line together with significant contour bulge (suggestive of placenta accreta spectrum, increta subtype), there were markedly increased regional vascularity and blurring of the urinary bladder wall but no evidence of gross intravesical extension. Prominent vascularity is also noted all over the cervical and peri-cervical regions, Figure 4 . The main uterine cavity proper showed no sacs and the uterus showed two fibroids, the largest $(3 \times 3 \mathrm{~cm})$ located at the upper aspect of the anterior uterine wall and having sub-mucosal extension.

When the diagnosis was made sure, the patient was transferred on 18/6/2021 to the tertiary referral hospital of the region $230 \mathrm{~km}$ away. On the transfer day, the patient started leaking liquor till it was drained, which continued for 6 days-the period she stayed under observation as they misdiagnose her condition for low lying placenta with possibility of accreta, and for consultant committee to discuss the case and options of management available. The patient received methotrexate IM injection on 20/6/2021 (1 mg/kg), she refused uterine artery embolization done under local anesthesia, asked desperately to keep her uterus and signed an informed consent for hysterectomy, blood products were 


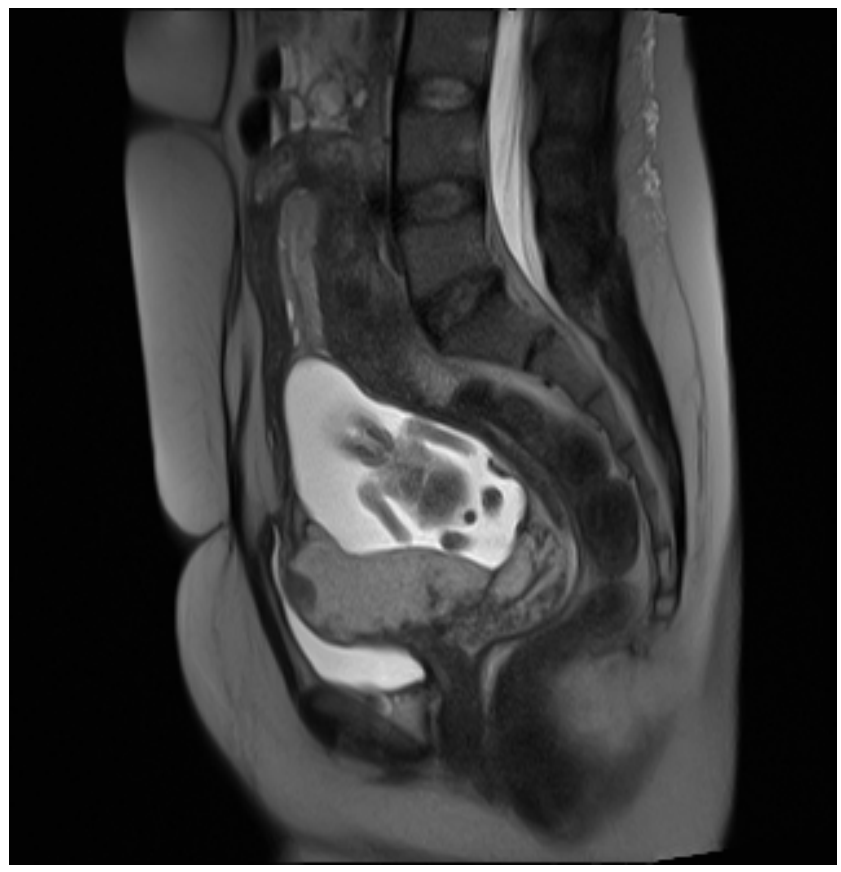

Figure 3. T2 weighted MRI image in sagittal plane, showing the 16 weeks fetus sitting peacefully in a markedly distended cervical canal and placenta implanted on the anterior aspect of it. The characteristic hour-glass uterus over-rides the pregnancy, with closed internal os and empty cavity.

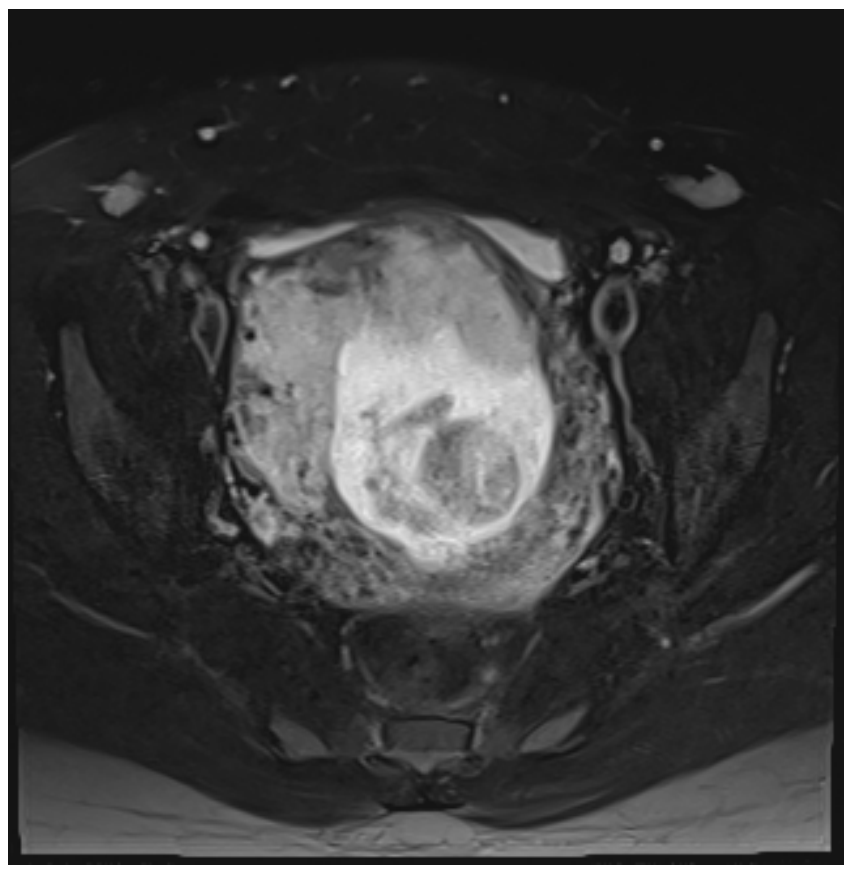

Figure 4. T2 weighted MRI image in transverse plane, showing focal interruptions of the myometrial line together with significant contour bulge suggestive of placenta increta, there were markedly increased regional vascularity and blurring of the urinary bladder wall but no evidence of gross intra-vesical extension. 
prepared and vascular and urology surgeons were informed to attend the planned major surgery.

On 23/6/2021 at 12:00 PM the surgical team started the operation; surprisingly aiming to preserve the uterus if they can. The operation took three stressful hours, during which they did a Pfannenstial incision, ligated the uterine arteries at the level of isthmus, used diathermy for dissection of the adherent bladder base from the anterior cervical wall, open the anterior cervical wall transversely, extract the dead fetus and manually separate the placenta. A considerable amount of bleeding from the placental bed resulted after removing it. Bakri ballon distended with $150 \mathrm{cc}$ of sterile saline solution was inserted through the abdominal incision into the bleeding cervix, the cervix was sutured with 2-0 vicryl sutures, and the bladder was checked for any injures and the abdomen was closed in layers with intra peritoneal drain insertion before closure. Transfusion of 4 units of blood and 2 units of plasma intra-operative was done and the patient was transmitted to intensive care unit (ICU) for observation and replacements till the fifth day post-operative. The drain collected $600 \mathrm{cc}$ fresh blood in the first 6 hours post-operative and around $200 \mathrm{cc}$ of blood lost vaginally, but the patient's condition stabilized gradually with the aid of replacements. Bakri ballon and urinary catheter were removed on day two post-operative and the intraabdominal drain was removed on the sixth day just before transmission from ICU to the inpatient ward. After one day inward, she was discharged home on $29^{\text {th }}$ of June, 2021.

Till 18/7/2021, the patient was stable with minimal vaginal spotting, no follow up was done or special post-operative instructions were given to her. Then she had a severe attack of painless vaginal bleeding again, transferred to her home area primary care hospital, vitally she was stable: pulse $107 \mathrm{~b} / \mathrm{min}, \mathrm{BP} 105 / 60, \mathrm{Hb}$ $10 \mathrm{~g} / \mathrm{dl}$ and her BHCG was $264 \mathrm{mIU} / \mathrm{ml}$. The cervix was ballooned and soft and vaginal was filled with blood clots by PV examination. TV-US revealed a heterogeneous mass $5 \mathrm{~cm}$ in diameter occupied the cervical canal and surrounded with increased vascularity. Resuscitation with IV fluids, hemostatics, 75 mg methotrexate IM injection, transfusion of one packed RBC unit and trial of vaginal packing, all were conducted to control bleeding then she was transferred immediately to operative room where the consultant examined the cervix under general anesthesia. There were remnants of placental tissue in the anterior cervical canal, firmly attached to it, manually removed, and then intractable bleeding occurred from the site of the remnants attachment. To control it, Babri balloon was inserted in cervix, filled with $150 \mathrm{ml}$ of saline then a tape cerclage was sutured at the level of the external os to fix it more. Vaginal packing with two towels was done and one unit of packed RBCs was given intra-operatively.

For the following 3 days, the patient was closely observed for vital signs, vaginal bleeding and CBC. Gradual deflation of the balloon was done then removed totally with the vaginal packs on $21 / 7 / 2021$. The cerclage was left in place for fear of any trauma to the fragile cervix. Her BHCG was $16 \mathrm{mIU} / \mathrm{ml}$ and $\mathrm{Hb}$ $10.5 \mathrm{gm} / \mathrm{dl}$. She was stable and discharged on the next day 22/7/2021. On 
26/7/2021 her BHCG was $8 \mathrm{mIU} / \mathrm{ml}$.

On 29/7/2021 she did a MRI with contrast examination for follow up. It showed an irregular soft tissue mass lesion centered upon the right anterolateral wall of cervix with both intra cervical and exophytic components, measuring about $4.5 \times 4.3 \times 4.0 \mathrm{~cm}$ in diameters, Figure 5 . The mass was presenting complex signal intensity in all pulse sequences and without contrast enhancement. The exophytic component appears adherent to lower posterior aspect of the urinary bladder without evidence of line of cleavage in between, with markedly thickened posterior vesical wall measuring about $0.6 \mathrm{~cm}$. No gross intravesical extension detected. The upper right side of the anterior cervical wall was seriously damaged and lacerated, but the left side, the external os and the posterior wall were perfectly healed and formed again, Figure 6. Her BHCG was 2.8 $\mathrm{mIU} / \mathrm{ml}$ and she had minimal vaginal spotting, so there was no need for any farther surgical interventions. The second Post-operative period went smoothly without any significant events. Twenty days afterwards, the cervix was perfectly reformed and cerculage was safely removed.

\section{Discussion}

CEP was first described in 1817, but in 1911 Rubin stated the histo-pathological criteria required for diagnosis of a cervical pregnancy. These three criteria

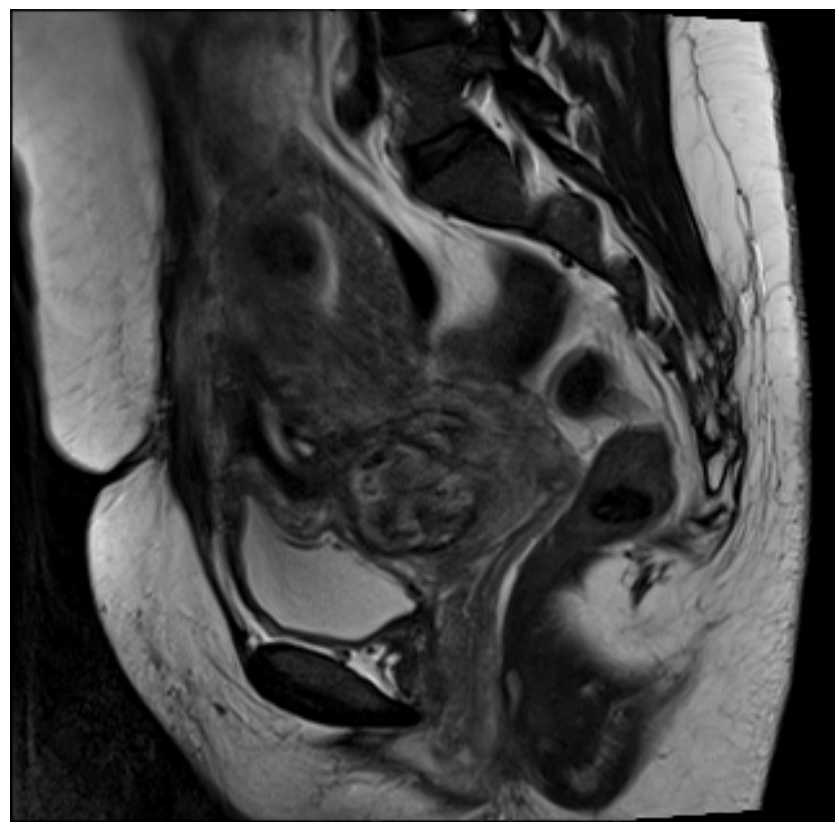

Figure 5. T2 weighted MRI image in sagittal plane, showing an irregular soft tissue mass lesion centered upon the right anterolateral wall of cervix with both intra cervical and exophytic components, measuring about $4.5 \times 4.3 \times 4.0 \mathrm{~cm}$ in diameters. The exophytic component appears adherent to lower posterior aspect of the urinary bladder without evidence of line of cleavage in between, with markedly thickened posterior vesical wall. No gross intravesical extension detected. 


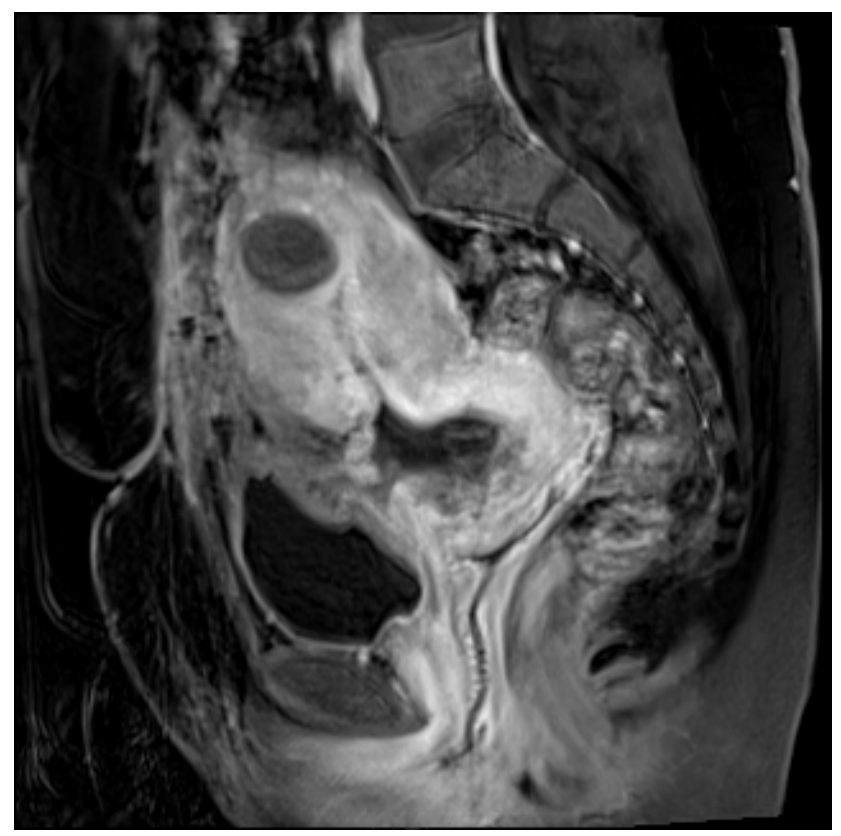

Figure 6. T1 weighted MRI image in sagittal plane, the right side of the anterior cervical wall was seriously damaged and lacerated, but the posterior wall was perfectly healed and formed again.

require hysterectomy specimens: 1) cervical glands must be opposite the placental attachment, 2) placental attachment to the cervix must be situated below the entrance of the uterine vessels or below the reflection of the anterior and posterior surface of the uterus and 3) fetal elements must be absent from the corpus uteri [8]. Because of the efficient early diagnosis of cervical pregnancy, more and more cases are managed conservatively without hysterectomies. So, the more practical criteria of Palman and McElin [9] are used now. The five items do not require hysterectomy for diagnosis and include: a) painless uterine bleeding, following a period of amenorrhoea, b) a soft enlarged cervix equal to or larger than the uterine body (an hour-glass shaped uterus), c) products of conception completely in and firmly attached to the endocervix, d) a closed internal os and e) a partially opened external os.

In 1997, Ushakov established ultraSonographic diagnostic criteria of CEP which are very clear and helpful distinguishing it from other similar conditions and include: 1) empty uterine cavity or thickened endometrium, 2) distended and/or enlarged cervical canal, 3) gestational sac or placental tissue below the level of the internal os, 4) negative "sliding organs sign" by transvaginal US, and 5) high peritrophoblastic vascularity on Doppler examination (peak velocity $>20$ $\mathrm{cm} / \mathrm{s}$, pulsatility index $<1.0)[10]$.

Differential Diagnosis of CEP include: incomplete abortion, cesarean scar ectopic pregnancy, abdominal ectopic pregnancy, cervical tumors, degenerated cervical leiomyoma, trophoblastic tumor or placenta previa [11] [12] [13]. According to Ushakov et al. [10], the accuracy of cervical pregnancy detection with 
a transvaginal scan is $87.5 \%$ of cases. Magnetic resonance imaging (MRI) is very useful in doubtful cases. Jung et al. [14] reported the characteristic MRI findings in CEP, which include an ill-marginated mass with very heterogenous signal intensity on T2-weighted images, irregular internal high-signal intensities on T1-weighted images, and a partial or circumferential rim of low-signal intensity.

In the present case, she was misdiagnosed as intrauterine from the early beginning (6 weeks gestation), despite the presence of all clinical and ultrasound criteria for diagnosis of CEP, The initial ultrasound was also inaccurate, It was done trans-abdominally and the diagnosis of a cervical ectopic pregnancy was not thought of at that time, missing a precious chance for early conservative treatment. Later, she was misdiagnosed again by her consultant as low-lying placenta and managed expectantly till she reached 16 weeks gestation and had another attack of painless bleeding. When MRI was done at last, the diagnosis of cervical ectopic was confirmed, but the opportunity of safe conservative management was forever lost.

There are no definite guidelines for optimal treatment options for stable patients with a cervical pregnancy due to the rarity of the clinical entity and lack of any retrospective studies. The success of conservative treatment depends on the early diagnosis by ultrasound, which can reduce the chances of a life threatening hemorrhage necessitating emergency hysterectomy or blood transfusion.

Conservative management includes the use of intramuscular methotrexate (MTX) and/or an intra-sac injection of potassium chloride. This is effective in $80 \%-90 \%$ of cases of early cervical pregnancy. Patient's criteria for methotrexate treatment include a hemo-dynamically stable patient and ectopic size of $3 \mathrm{~cm}$ or less [15]. Relative contraindications for MTX are similar to other types of ectopic, like tubal and ovarian pregnancies. Failure rate will be increased in cases with a gestational age $\geq 9$ weeks, beta hCG $\geq 10,000 \mathrm{mIU} / \mathrm{mL}$, crown-rump length $>10 \mathrm{~mm}$, or cardiac activity [16] [17]. The multidose regimen is usually preferred, i.e. $1.0 \mathrm{mg} / \mathrm{kg}$ body weight on days $1,3,5$ and 7 interspaced by leucoverin $0.1 \mathrm{mg} / \mathrm{kg}$ body weight. According to a retrospective study, methotrexate chemotherapy in cervical pregnancy did not affect the reproductive performance of these patients later on [18]. Monteagudo et al. successfully terminated a heterotopic cervical pregnancy with an intra-sac injection of potassium chloride, leaving the intrauterine pregnancy intact [19].

Uterine artery embolization (UAE) is an alternative option for conservative management when MTX is not suitable or not tolerated. According to Zakaria et al., it is to be used for cervical pregnancies when BHCG is more than 34,000 $\mathrm{mIU} / \mathrm{mL}$, but may be complicated with uterine infarction, necrosis of the bladder or the rectum and sciatic nerve injury [20].

Surgical treatment strategies of CEP rages widely from suction curettage up to hysterectomy, and the selection of the management plan depends mainly on the gestational age of the pregnancy, the willing of future fertility and the hemodynamics of the patient at the moment of diagnosis. For example, an early intact pregnancy of a patient who desires to keep her uterus, evacuation via suction 
curettage may be tried, and control of bleeding can be achieved by tamponade of the uterine cervix with a Foleys' catheter, Bakri balloon or vaginal packing [21]. Hysteroscopic resection with simultaneous ablation ofbleeding vessels is a potentially safe and effective option for this patient as it allows direct visualization and resection of the ectopic gestation.

For decades, the classical treatment for CEP was hysterectomy, and it will remain the suitable treatment for advanced gestations and shocked patients. In 1968, Mortimer and Aiken said: "cervical gestations in excess of eight weeks are best treated by abdominal hysterectomy" [22], and in 2013, Singh observed that one hundred percent of documented cervical pregnancies beyond 12 weeks' gestation essentially required hysterectomy [23]. The present case was-by all means-indicated for hysterectomy, as the pregnancy reached almost seventeen weeks and there was evidence of adherent placenta accrete by MRI. She suffered two attaches of severe life threatening bleeding, went to operative room twice, transfused several units of blood and admitted to the ICU, but the uterus was preserved at last.

By reviewing the literature, there were few similar cases. A fourteen weeks gestation was managed conservatively by a combination of Ultrasound-guided fetal intrathoracic potassium chloride $(\mathrm{KCl})$ injection, Amniocentesis, Ultrasoundguided $\mathrm{D} \& \mathrm{C}$ and a purse-string suture placed just below the cervico-vaginal reflection for hemostasis of the vascular bed, in a technique similar to a McDonald cerclage [24]. Another case of a primi-gravida at 24 weeks, complained of an attack of vaginal bleeding with abdominal pain, and was diagnosed as a case of an inevitable abortion. After termination of the pregnancy, intractable and uncontrolled bleeding was noticed, so laparotomy was done and a diagnosis of cervical ectopic pregnancy was confirmed and necessitated immediate total abdominal hysterectomy [25].

\section{Conclusion}

When discovered late, CEP represents a major life threating condition. Conservative management for those particular cases-although seems possible-but it really exposes the patients to such a dangerous gamble on their lives. More efforts should be exerted in the direction of early diagnosis of the problem before it becomes a catastrophe, by keeping CEP in the differential diagnosis of bleeding in early pregnancy, and remembering the golden statement that said: "The majority of Obstetricians will never see a cervical pregnancy; the minority who do encounter this complication will wish they had not" [26].

\section{Author Contribution}

1) Suzan Elsharkawy, Abdullah Elrashidy: collection of data and manuscript writing.

2) Ashraf Elaggan, Amr Mostafa: radiology diagnosis.

3) Nazem Badran, Gawed Ekbal, Shahda Yakob: first intervention surgical 
team.

4) Salamah Elnagar, Mohamed Abdelaziz: second intervention surgical team.

\section{Conflicts of Interest}

The authors declare that they have no conflicts of interest.

\section{References}

[1] Celik, C., Baka, A.A., Cezgine, K. and Akyurek, C. (2003) Methotrexate for Cervical Pregnancy. A Case Report. The Journal of Reproductive Medicine, 48, 130-132.

[2] Hosni, M.M., Herath, R.P. and Rashid, M. (2014) Diagnostic and Therapeutic Dilemmas of Cervical Ectopic Pregnancy. Obstetrical \& Gynecological Survey, 69, 261-276. https://doi.org/10.1097/OGX.0000000000000062

[3] Taylor, J.E., Yalcinkaya, T.M. and Akar, M.E. (2011) Successful Conservative Management of Cervical Ectopic Pregnancy: A Case Series. Archives of Gynecology and Obstetrics, 283, 1215-1217. https://doi.org/10.1007/s00404-010-1529-7

[4] Shinagawa, S. and Nagayama, M. (1969) Cervical Pregnancy as Possible Sequela of Induced Abortion. Report of 19 Cases. American Journal of Obstetrics \& Gynecology, 105, 282-284. https://doi.org/10.1016/0002-9378(69)90075-1

[5] Weyerman, P.C., Verhoeven, A.T. and Alberda, A.T. (1989) Cervical Pregnancy after In-Vitro Fertilization and Embryo Transfer. American Journal of Obstetrics \& Gynecology, 161, 1145-1147. https://doi.org/10.1016/0002-9378(89)90652-2

[6] Tejero, C., Ortega, M., Royo, B., Pilar, A., Lapresta, M., et al. (2010) Gestación ectópica cervical tratada mediante punción ecoguiada intrasacular de metotrexato. Revista Chilena de Obstetricia y Ginecología, 75, 325-328. https://doi.org/10.4067/S0717-75262010000500009

[7] Shavell, V., Ebdallah, M., Zakaria, M., Berman, J., Diamond, M., et al. (2012) Misdiagnosis of Cervical Ectopic Pregnancy. Archives of Gynecology and Obstetrics, 285, 423-426. https://doi.org/10.1007/s00404-011-1980-0

[8] Rubin, I.C. (1911) Cervical Pregnancy. Surgery, Gynecology and Obstetrics, 13, 625.

[9] Varghese, U., Fajardo, A. and Gomathinayagam, T. (2008) Cervical Pregnancy. Oman Medical Journal, 23, 53-54.

[10] Ushakov, F.B., Elchalal, U., Aceman, P.J. and Schenker, J.G. (1997) Cervical Pregnancy: Past and Future. Obstetrical \& Gynecological Survey, 52, 45-49. https://doi.org/10.1097/00006254-199701000-00023

[11] Jaswal, T., Sunita, S., Smiti, N., Sagwan, K., Chauhan, M., et al. (2002) Cervicalectopic Pregnancy with Placenta Percreta and Bladder Wall Invasion. Acta Obstetricia et Gynecologica Scandinavica, 81, 991-992. https://doi.org/10.1034/j.1600-0412.2002.811018.x

[12] Cherng, J., Ma-Lee, K. and Shen, J. (2007) Transvaginal Ultrasound-Guided Treatment of Cervical Pregnancy. Obstetrics \& Gynecology, 109, 1076-1082.

https://doi.org/10.1097/01.AOG.0000262052.09350.52

[13] Sherer, D., Gorelick, C., Dalloul, M., Sokolovski, M. and Kheyman, M. (2008) Three-Dimensional Sonographic Findings of a Cervical Pregnancy. Journal of UItrasound in Medicine, 27, 155-158. https://doi.org/10.7863/jum.2008.27.1.155

[14] Jung, S.E., Byun, J.Y., Lee, J.M., Lee, J.M., Choi, B.G. and Hahn, S.T. (2001) Characteristic MR Findings of Cervical Pregnancy. Journal of Magnetic Resonance Imaging, 13, 918-922. https://doi.org/10.1002/jmri.1131 
[15] Slaughter, J.L. and Grimes, D.A. (1995) Methotrexate Therapy-Non Surgical Management of Ectopic Pregnancy. Western Journal of Medicine, 162, 225-228.

[16] Hung, T.H., Shau, W.Y., Hsieh, T.T., Hsu, J.J., Soong, Y.K. and Jeng, C.J. (1998) Prognostic Factors for an Unsatisfactory Primary Methotrexate Treatment of Cervical Pregnancy: A Quantitative Review. Human Reproduction, 13, 2636-2642. https://doi.org/10.1093/humrep/13.9.2636

[17] Cunningham, F.G., Leveno, K.J., Bloom, S.L., et al. (2018) Williams Obstetrics. 25th Edition, McGraw-Hill Education, London.

[18] Kung, F.T. and Chang, S.Y. (1999) Efficacy of Methotrexate Treatment in Viable and Nonviable Cervical Pregnancies. American Journal of Obstetrics \& Gynecology, 181, 1438-1444. https://doi.org/10.1016/S0002-9378(99)70389-3

[19] Monteagudo, A., Tarricone, N.J., Timor-Tritsch, I.E. and Lerner, J.P. (1996) Successful Transvaginal Ultrasound-Guided Puncture and Injection of a Cervical Pregnancy in a Patient with Simultaneous Intrauterine Pregnancy and a History of a Previous Cervical Pregnancy. Ultrasound in Obstetrics \& Gynecology, 8, 381-386. https://doi.org/10.1046/j.1469-0705.1997.08060381.x

[20] Zakaria, M.A., Abdallah, M.E., Shavell, V.I., Berman, J.M., Diamond, M.P. and Kmak, D.C. (2011) Conservative Management of Cervical Ectopic Pregnancy: Utility of Uterine Artery Embolization. Fertility and Sterility, 95, 872-876. https://doi.org/10.1016/j.fertnstert.2010.12.024

[21] Sharma, A., Ojha, R., Mondal, S., Cha opadhyay, S. and Sengupta, P. (2013) Cervical Intramural Pregnancy: Report of a Rare Case. Nigerian Medical Journal, 54, 271-273. https://doi.org/10.4103/0300-1652.119670

[22] Mortimer, C.W. and Aiken, D.A. (1968) Cervical Pregnancy. Journal of Obstetrics and Gynaecology of the British Commonwealth, 75, 741-745. https://doi.org/10.1111/j.1471-0528.1968.tb01554.x

[23] Singh, S. (2013) Diagnosis and Management of Cervical Ectopic Pregnancy. Journal of Human Reproductive Sciences, 6, 273-276. https://doi.org/10.4103/0974-1208.126312

[24] Handley, K.F., Bergeron, L.M. and Biggio, J.R. (2020) Conservative Management of a Second-Trimester Cervical Ectopic Pregnancy. Ochsner Journal, 20, 459-462. https://doi.org/10.31486/toj.20.0034

[25] Etraim, A., Eljabu, H., Elfortia, I. and Andisha, A. (2021) Delayed Diagnosis and Management of Second Trimester Cervical Ectopic Pregnancy-Case Report. Health Science Journals, 15, 785 .

[26] Mortimer, C. and Aiken, D. (1968) Cervical Pregnancy. Journal of Obstetrics and Gynaecology, 75, 741-745. https://doi.org/10.1111/j.1471-0528.1968.tb01554.x 